\title{
Ethnic analogies and differences in fetal heart rate variability signal: A retrospective study
}

\author{
Salvatore Tagliaferri ${ }^{1}$, Francesca Giovanna Esposito ${ }^{1}$, Rosa Fagioli ${ }^{1}$, Marco Di Cresce ${ }^{2}$, \\ Lucia Sacchi $^{2}$, Maria Gabriella Signorini ${ }^{3}$, Marta Campanile ${ }^{1}$, Pasquale Martinelli ${ }^{1}$ and \\ Giovanni Magenes ${ }^{2}$ \\ ${ }^{1}$ Department of Obstetrical-Gynaecological and Urological Science and Reproductive Medicine, Federico II University, Naples, \\ ${ }^{2}$ Department of Electrical, Computer and Biomedical Engineering, University of Pavia, Pavia, and ${ }^{3}$ Department of Electronics, \\ Information and Bioengineering, Polytechnic of Milan, Milan, Italy
}

\begin{abstract}
Aim: We aimed to analyze computerized cardiotocographic (cCTG) parameters (including fetal heart rate baseline, short-term variability, Delta, long-term irregularity [LTI], interval index [II], low frequency [LF], movement frequency $[\mathrm{MF}]$, high frequency $[\mathrm{HF}]$, and approximate entropy [ApEn]) in physiological term pregnancies in order to correlate them with ethnic differences. The clinical meaning of numerical parameters may explain physiological or paraphysiological phenomena that occur in fetuses of different ethnic origins.

Methods: A total of 696 pregnant women, including 384 from Europe, 246 from sub-Saharan Africa, 45 from South-East Asia, and 21 from South America, were monitored from the 37th to the 41st week of gestation. Statistical analysis was performed with the analysis of variance test, Pearson correlation test and receiver-operator curves $(P<0.05)$.

Results: Our results showed statistically significant differences $(P<0.05)$ between white and black women for Delta, LTI, LF, MF, HF, and ApEn; between white and Asian women for Delta, LTI, MF, and the LF/(HF + MF) ratio; and between white and Latina women for Delta, LTI, and ApEn. In particular, Delta and LTI performed better in the white group than in the black, Asian, and Latina groups. Instead, LF, MF, HF, and ApEn performed better in the black than in the white group.

Conclusion: Our results confirmed the integrity and normal functionality of both central and autonomic nervous system components for all fetuses investigated. Therefore, CTG monitoring should include both linear and nonlinear components of fetal heart rate variability in order to avoid misinterpretations of the CTG trace among ethnic groups.
\end{abstract}

Key words: African continental ancestry group, Asian continental ancestry group, computer-assisted, fetal monitoring, signal interpretation, spectrum analysis.

\section{Introduction}

Electronic fetal heart rate (FHR) monitoring is the most widespread non-invasive method to evaluate fetal wellbeing during the antenatal period, especially in high-risk pregnancies.

Computerized cardiotocography (cCTG) was developed to reduce the great inter- and intra-observer variability of visual analysis. ${ }^{1}$ cCTG is characterized by objectivity and consistency as it performs a quantitative automatic trace analysis, implementing diagnostic criteria accepted in clinical obstetric practice.

Many efforts have been made to understand the mechanisms of normal regulation of FHR variability and several studies have found that they are both linear and nonlinear. cCTG provides a standardized method to

Received: February 212016.

Accepted: September 232016.

Correspondence: Dr Salvatore Tagliaferri, Department of Obstetrical-Gynaecological and Urological Science and Reproductive Medicine,

Federico II University, Via Pansini 5, 80131 Naples, Italy. Email: salvatoretagliaferri@libero.it 
evaluate quantitative measures of linear and nonlinear indices of FHR variability. ${ }^{2}$

Very few studies have investigated the influence of the maternal ethnic origin on FHR variability and, to our knowledge, no one has evaluated its nonlinear characteristics. $^{3,4}$

This study was performed to describe the changes in FHR variability through the most recent investigated measures of spectral analysis and entropy in term physiological pregnancies, according to ethnic differences.

The results of this study could be useful for identifying misinterpreted FHR recordings and to assist clinicians in the management of pregnancy. ${ }^{5}$

Moreover, the clinical meaning of numerical parameters could provide new information about physiological or paraphysiological phenomena that occur in fetuses of different ethnic origins.

\section{Methods}

This retrospective study was carried out at the Department of Obstetrical-Gynaecological and Urological Science and Reproductive Medicine, Federico II University, Naples, Italy, where we collected cCTG data from 4365 pregnant women who underwent routine antenatal monitoring. The principles of the Helsinki Declaration were followed, and all participants gave their written informed consent.

Cases were enrolled if they fulfilled the following inclusion criteria: singleton low-risk pregnancy; certain pregnancy dating (calculated from the first day of the last menstrual period and confirmed by ultrasound measurements, according to the population nomograms); ${ }^{6}$ absence of pre-existing maternal diseases and pregnancy-related diseases, drug abuse, and cigarette smoking; a body mass index (BMI) $>20$ and $<30$ at the beginning of pregnancy; gestational age at the CCTG recording $>37$ th and $<41$ st week; time between the last meal and the FHR recording $<4 \mathrm{~h}$; cCTG with a signal loss of $<15 \%$ over the whole record. ${ }^{7-9}$

Newborn baby data (sex, weight, Apgar score, malformation at birth, admission to neonatal intensive care, and umbilical artery $\mathrm{pH}$ ) were also collected. We excluded fetuses with chromosomal and major congenital anomalies, abnormal umbilical artery Doppler, birthweight $<10^{\text {th }}$ and $>90^{\text {th }}$ percentile according to the population nomograms, and inadequate umbilical cord samples at birth. ${ }^{10,11}$

As a result, a homogeneous population of 696 pregnant women, including 384 white women from Europe,
246 black women from sub-Saharan Africa, 45 women from South-East Asia, and 21 Latina women from South America, was enrolled in this study. The cCTG monitoring was made with the same frequency in all cases. Only one recording per fetus was analyzed and the selected cCTG trace was the last performed within $24 \mathrm{~h}$ of delivery.

\section{Signal acquisition}

Antepartum cCTG monitoring was performed in a controlled clinical environment with the patient lying in a semi-Fowler's position in a relaxed condition. The cCTG records were obtained using Corometrics 170 (General Electrics), equipped with an ultrasound transducer and a transabdominal tocodynamometer.

The cardiotocograph was interfaced to the 2CTG2 system, ${ }^{12}$ which is able to perform a computerized analysis on 3-min segments of recording. The FHR records were performed according to the guidelines of the Royal College of Obstetricians and Gynaecologists ${ }^{13}$ and the FHR analysis was carried out using 3-min segments (360 data points) without missing data, in order to prevent influences of incorrect heart rates and to obtain the same length of analysis segment for all parameters investigated, irrespective of the trace length. The initial, the middle and the final 3 min of each trace were averaged, in order to obtain a single analysis segment for each trace.

The HP fetal monitors use an autocorrelation technique to compare the demodulated Doppler signal of a heartbeat with the next one. Each Doppler signal is sampled at $200 \mathrm{~Hz}$ (5 ms). The time window over which the autocorrelation function is computed is $1.2 \mathrm{~s}$, corresponding to a FHR lower bound of 50 b.p.m. Peak detection software then determines the heart period (the equivalent of RR period) from the autocorrelation function. With a peak position interpolation algorithm, the effective resolution is better than $2 \mathrm{~ms}$.

The HP monitor produces an FHR value in b.p.m. every $250 \mathrm{~ms}$. In the commercially available system, the PC reads 10 consecutive values from the monitor every $2.5 \mathrm{~s}$ and determines the actual FHR as the average of the 10 values (corresponding to an equivalent sampling frequency of $0.4 \mathrm{~Hz}$ ). We used modified software in order to read the FHR at $2 \mathrm{~Hz}$ (every $0.5 \mathrm{~s}$ ). The choice of reading the FHR values each $0.5 \mathrm{~s}$ represents a reasonable compromise to achieve a large enough bandwidth (Nyquist Frequency $1 \mathrm{~Hz}$ ) and an acceptable accuracy of the FHR signal.

The parameters selected to quantify the complexity characteristics of the FHR series were both linear and 
nonlinear. Linear parameters were time domain parameters (FHR baseline [baseline]; short-term variability [STV]; Delta; long-term irregularity [LTI]; and interval index [II]) and frequency domain parameters (low frequency [LF]; movement frequency [MF]; high frequency $[\mathrm{HF}]$; and $\mathrm{LF} /[\mathrm{HF}+\mathrm{MF}]$ ratio). From nonlinear parameters, approximate entropy (ApEn) was selected. ${ }^{14,15}$

\section{Time domain parameters}

\section{Baseline}

The baseline is a running average of the heart rate where accelerations and decelerations are defined as deviations of the FHR from the baseline lasting a sufficient amount of time. In an automated system for the evaluation of the CTG recordings, a reproducible determination of the baseline is fundamental. We used a real-time version of Mantel's algorithm. ${ }^{16}$

\section{STV}

STV quantifies FHR variability over a very short time scale on a beat-to-beat basis. ${ }^{12}$ Considering $1 \mathrm{~min}$ of interbeat sequence, T24 (i) in ms, $i=1, \ldots, 24$, we defined STV as:

$$
\begin{aligned}
S T V & =\text { mean }\left[\left|T_{24}(i+1)-T_{24}(i)\right|\right]_{i} \\
& =\frac{\sum_{i=1}^{23}\left|T_{24}(i+1)-T_{24}(i)\right|}{23},
\end{aligned}
$$

where T24 (i) is the value of the signal T (i) taken each $2.5 \mathrm{~s}$.

\section{Delta}

Given a minute of signal in milliseconds T24(i) with $i \in[1$; 24], Delta is defined as the difference between the maximum and minimum FHR value:

Delta $=\operatorname{maxT}_{24}(\mathrm{i})-\operatorname{minT}_{24}(\mathrm{i})$.

Arduini et al. ${ }^{12}$ exclude big accelerations and decelerations from the calculation.

\section{LTI}

LTI is computed on a 3-min segment of interbeat sequence in milliseconds. Given a signal T24(i) with $i \in[1 ; 72]$, LTI is defined as the interquartile range $(1 / 4$; $3 / 4$ ) of the distribution of the modula m24( j) with $i \in[1 ; 71]$.

$m_{24}(j)=\left(\mathrm{T}_{24}{ }^{2}(\mathrm{j}+1)+\mathrm{T}_{24}{ }^{2}(\mathrm{j})\right)^{1 / 2}$.

The definition is the same provided by de Haan et al. ${ }^{17}$ with the exception of a window of 72 (and not 512) samples long. Arduini et al. ${ }^{12}$ exclude big accelerations and decelerations from the calculation.
II

II is calculated as the coefficient of variation between the differences of all FHR values in $1 \mathrm{~min}$ of interbeat sequence, taken each $2.5 \mathrm{~s}$. It was proposed by Yeh et al. ${ }^{18}$ as a long-term variability statistic. We adopted the formulation used by Arduini $e t$ al. ${ }^{12}$ as follows:

$I I=\frac{s t d\left[T_{24}(i+1)-T_{24}(i)\right]}{S T V} \quad i=1, \ldots, 23$.

\section{Frequency domain parameters}

\section{Power spectral analysis of FHR variability}

The Power Spectrum of FHR variability can be quantified during the period of activity and fetal sleep by the use of mathematical algorithms in the following frequency ranges: LF, $0.03-0.15 \mathrm{~Hz} ; \mathrm{MF}, 0.15-0.50 \mathrm{~Hz}$ (not present in adult human subjects); and HF, $0.50-1.00 \mathrm{~Hz}$. LF and HF bands are associated with autonomic nervous system (ANS) activity (mainly the sympathetic and parasympathetic branches, respectively) while the MF band is connected to fetal movements and maternal respiratory frequency. The $\mathrm{LF} /(\mathrm{HF}+\mathrm{MF})$ ratio was also estimated as well and it quantifies the autonomic balance between neural control mechanisms from different origins (in accordance with the LF/HF ratio normally calculated in adults). For a detailed description of how these parameters are computed, please refer to Signorini et $a l .^{2}$

\section{Nonlinear parameters}

ApEn

ApEn is a nonlinear measure obtained through direct signal estimation, capable of quantifying the complexity (or irregularity) of FHR variability over 3-min windows of FHR signal: small values indicate reduced signal irregularity. We use the original definition by Pincus ${ }^{19}$ :

$$
\begin{aligned}
\operatorname{ApEn}_{-}(\mathrm{m}, \mathrm{r}) & =\frac{\sum_{i=1}^{N-m+1} \log C i(m, r)}{N-m+1} \\
& -\frac{\sum_{i=1}^{N-m} \log C i(m+1, r)}{N-m} .
\end{aligned}
$$

For an experimental time series of a fixed length $N, m$ is the length of runs compared in the time series, $r$ is the percentage of signal std (working as a filter) and Ci measures the regularity of patterns comparing them to a given pattern of length $m$.

\section{Statistics}

Data statistical analysis was performed using SPSS 19.0 for Windows. The Kolmogorov-Smirnov test showed 
Gaussian distributions in each population for all parameters investigated. The $t$-test was applied for continuous variables while the $\chi^{2}$-test was used for categorical variables. cCTG parameters were compared among groups using the one-way analysis of variance (ANOVA) test. The ANOVA test with the Bonferroni adjusted $\alpha$ was used for pairwise comparisons between groups. Moreover, some cCTG parameters were correlated with each other using the Pearson correlation test. To complete our analysis, receiver-operator curves (ROC) and specificity were obtained. Statistical significance was $P$-value $<0.05$ for all the tests performed.

\section{Results}

The demographic and clinical characteristics by ethnic distribution of our population are shown in Table 1 . No maternal or neonatal data differences were observed among groups $(P<0.05)$. Fetal $\mathrm{pH}$ at birth and the Apgar score were both in the range of normality. No statistical differences were found with respect to the sexes of newborns.

The aim of the study was to identify which parameter or parameter set was most efficient in the discrimination among fetuses of different ethnic groups. The one-way ANOVA test showed statistically significant differences for most of the CCTG parameters investigated (Table 2). Among the time domain parameters, Delta $(F=21.20$; $P<0.001)$ and LTI $(F=88.46 ; P<0.001)$ showed great performance in the discrimination task while no differences were found for baseline, STV, or II. Both the spectral analysis and the entropy estimators were different among groups: $\mathrm{LF}(F=20.42 ; P<0.001), \mathrm{MF}$
$(F=10.19 ; P<0.001), \mathrm{HF}(F=19.25 ; P<0.001)$, $\mathrm{LF} /(\mathrm{HF}+\mathrm{MF})$ ratio $(F=5.92 ; P=0.001)$, and ApEn $(F=25.75 ; P<0.001)$.

Pairwise comparisons, using the one-way ANOVA test with the Bonferroni adjusted $\alpha$ showed statistically significant differences between white and black women for Delta, LTI, LF, MF, HF, and ApEn. Statistical differences were found between white and Asian women for Delta, LTI, MF, and the LF/(HF + MF) ratio; and statistical differences were found between white and Latina women for Delta, LTI, and ApEn (Table 2).

Moreover, statistically significant differences were found between black and Asian women for LF, MF, HF, the $\mathrm{LF} /(\mathrm{HF}+\mathrm{MF})$ ratio, and ApEn; between black and Latina women for LF, HF, and ApEn; and between Asian and Latina women for MF and ApEn (data not shown).

In order to check whether our results were affected by the fetal status or by intrasubject variability, we selected a subset of our population composed of 10 pregnant women of each race and we computed the relevant parameters for each recording in three separate segments of $3 \mathrm{~min}$ each after identifying $2 \mathrm{~F}$ fetal state. We performed mixed-effects ANOVA considering the segment as the within-subjects factor (three repeated measures) and the race as the between-subjects factor.

In summary, this further analysis revealed no significant intrasubject effects for almost all parameters. Only LTI showed a significant segment effect and a significant effect of the interaction between the two factors.

In order to improve the diagnostic ability of our set of parameters, we quantified the correlation between cCTG parameters for each ethnic group (Table 3). Among white pregnant women, ApEn showed a negative

Table 1 Maternal and perinatal characteristics

\begin{tabular}{|c|c|c|c|c|c|}
\hline Characteristics & White & Black & Asian & Latina & $P$-value \\
\hline Age (years) & $28.73 \pm 5.0$ & $29.83 \pm 4.7$ & $29.36 \pm 5.0$ & $27.85 \pm 8.0$ & 0.1 \\
\hline Body mass index $\left(\mathrm{kg} / \mathrm{m}^{2}\right)$ & $25.2 \pm 4.7$ & $26.4 \pm 3.5$ & $24.7 \pm 4.2$ & $26.3 \pm 3.6$ & 0.08 \\
\hline Weight gain $(\mathrm{kg})$ & $8.6 \pm 7.3$ & $9.8 \pm 8.2$ & $8.2 \pm 7.1$ & $9.5 \pm 7.8$ & 0.07 \\
\hline Gravidity & $1.21 \pm 1.0$ & $1.40 \pm 0.9$ & $1.31 \pm 0.8$ & $1.36 \pm 0.7$ & 0.09 \\
\hline Parity & $0.7 \pm 0.3$ & $0.8 \pm 0.4$ & $0.6 \pm 0.4$ & $0.9 \pm 0.6$ & 0.1 \\
\hline Gestational age at cCTG recording (weeks) & $39.1 \pm 1.7$ & $39.2 \pm 1.5$ & $39.5 \pm 1.4$ & $39.3 \pm 1.6$ & 0.2 \\
\hline Gestational age at delivery (weeks) & $39.5 \pm 1.9$ & $39.3 \pm 2.1$ & $39.8 \pm 1.5$ & $39.7 \pm 1.6$ & 0.1 \\
\hline Vaginal delivery $(\%)$ & 64.2 & 64.6 & 64.3 & 71.4 & 0.6 \\
\hline \multicolumn{6}{|l|}{ Neonatal data } \\
\hline Fetal $\mathrm{pH}$ at birth & $7.28 \pm 0.06$ & $7.29 \pm 0.07$ & $7.28 \pm 0.09$ & $7.29 \pm 0.05$ & 0.3 \\
\hline 1-min Apgar score & $7.8 \pm 0.9$ & $7.5 \pm 1.0$ & $7.4 \pm 0.8$ & $7.6 \pm 0.5$ & 0.2 \\
\hline 5-min Apgar score & $8.8 \pm 0.7$ & $8.8 \pm 1.2$ & $8.7 \pm 0.9$ & $8.3 \pm 0.6$ & 0.4 \\
\hline Female $(\%)$ & 52.3 & 48.0 & 42.8 & 57.1 & 0.3 \\
\hline Birthweight, $g$ & $3275 \pm 710$ & $3241 \pm 682$ & $3210 \pm 725$ & $3253 \pm 678$ & 0.09 \\
\hline
\end{tabular}

Values are expressed as mean value \pm SD. cCTG, computerized cardiotocographic. 
Table 2 Comparison between cCTG parameters stratified by ethnicity

\begin{tabular}{|c|c|c|c|c|c|c|}
\hline Variable & & $\begin{array}{l}\text { White } \\
\text { Group A }\end{array}$ & $\begin{array}{l}\text { Black } \\
\text { Group B }\end{array}$ & $\begin{array}{l}\text { Asian } \\
\text { Group C }\end{array}$ & $\begin{array}{l}\text { Latina } \\
\text { Group D }\end{array}$ & $P$-value* \\
\hline Baseline (b.p.m.) & $\begin{array}{l}\text { Mean } \\
\text { SD }\end{array}$ & $\begin{array}{r}138.03 \\
12.90\end{array}$ & $\begin{array}{r}139.84 \\
7.82\end{array}$ & $\begin{array}{r}136.78 \\
8.19\end{array}$ & $\begin{array}{r}141.80 \\
7.83\end{array}$ & $\begin{array}{l}0.045 \\
0.514^{\mathrm{A}-\mathrm{B}} \\
1.0^{\mathrm{A}-\mathrm{C}} \\
0.625^{\mathrm{A}-\mathrm{D}} \\
0.118\end{array}$ \\
\hline STV (ms) & $\begin{array}{l}\text { Mean } \\
\text { SD }\end{array}$ & $\begin{array}{l}6.37 \\
2.18\end{array}$ & $\begin{array}{l}5.99 \\
2.96\end{array}$ & $\begin{array}{l}5.79 \\
1.91\end{array}$ & $\begin{array}{l}5.65 \\
1.66\end{array}$ & $\begin{array}{l}0.346^{\mathrm{A}-\mathrm{B}} \\
0.804^{\mathrm{A}-\mathrm{C}} \\
1.0^{\mathrm{A}-\mathrm{D}} \\
<\mathbf{0 . 0 0 1}\end{array}$ \\
\hline Delta (ms) & $\begin{array}{l}\text { Mean } \\
\text { SD }\end{array}$ & $\begin{array}{l}30.05 \\
12.32\end{array}$ & $\begin{array}{l}36.64 \\
10.18\end{array}$ & $\begin{array}{l}38.22 \\
10.10\end{array}$ & $\begin{array}{l}37.93 \\
10.41\end{array}$ & $\begin{array}{r}<0.001^{\mathrm{A}-\mathrm{B}} \\
<0.001^{\mathrm{A}-\mathrm{C}} \\
\mathbf{0 . 0 1 3}^{\mathrm{A}-\mathrm{D}} \\
<0.001\end{array}$ \\
\hline LTI (ms) & $\begin{array}{l}\text { Mean } \\
\text { SD }\end{array}$ & $\begin{array}{l}33.62 \\
13.64\end{array}$ & $\begin{array}{r}19.68 \\
5.49\end{array}$ & $\begin{array}{r}22.39 \\
6.54\end{array}$ & $\begin{array}{r}22.80 \\
4.48\end{array}$ & $\begin{aligned} &<0.0011^{\mathrm{A}-\mathrm{B}} \\
&<\mathbf{0 . 0 0 1}^{\mathrm{A}-\mathrm{C}} \\
&<\mathbf{0 . 0 0 1} \\
& \\
& 0.628\end{aligned}$ \\
\hline II & $\begin{array}{l}\text { Mean } \\
\text { SD }\end{array}$ & $\begin{array}{l}0.87 \\
0.46\end{array}$ & $\begin{array}{l}0.84 \\
0.06\end{array}$ & $\begin{array}{l}0.82 \\
0.05\end{array}$ & $\begin{array}{l}0.84 \\
0.05\end{array}$ & $\begin{array}{l}1.0^{\mathrm{A}-\mathrm{B}} \\
1.0^{\mathrm{A}-\mathrm{C}} \\
1.0^{\mathrm{A}-\mathrm{D}}\end{array}$ \\
\hline $\mathrm{LF}\left(\mathrm{ms}^{2}\right)$ & $\begin{array}{l}\text { Mean } \\
\text { SD }\end{array}$ & $\begin{array}{r}82.36 \\
4.61\end{array}$ & $\begin{array}{r}79.58 \\
5.73\end{array}$ & $\begin{array}{r}84.29 \\
4.46\end{array}$ & $\begin{array}{r}82.70 \\
6.03\end{array}$ & $\begin{aligned}<0.001 \\
<0.001^{\mathrm{A}-\mathrm{B}} \\
0.095^{\mathrm{A}-\mathrm{C}} \\
1.0^{\mathrm{A}-\mathrm{D}} \\
<\mathbf{0 . 0 0 1}\end{aligned}$ \\
\hline $\operatorname{MF}\left(\mathrm{ms}^{2}\right)$ & $\begin{array}{l}\text { Mean } \\
\text { SD }\end{array}$ & $\begin{array}{r}12.27 \\
3.33\end{array}$ & $\begin{array}{r}13.28 \\
3.61\end{array}$ & $\begin{array}{r}10.44 \\
3.22\end{array}$ & $\begin{array}{r}13.13 \\
4.68\end{array}$ & 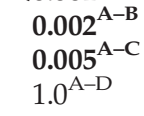 \\
\hline $\mathrm{HF}\left(\mathrm{ms}^{2}\right)$ & $\begin{array}{l}\text { Mean } \\
\text { SD }\end{array}$ & $\begin{array}{l}5.35 \\
2.82\end{array}$ & $\begin{array}{l}7.15 \\
3.82\end{array}$ & $\begin{array}{l}5.27 \\
2.27\end{array}$ & $\begin{array}{l}4.17 \\
2.79\end{array}$ & $\begin{aligned}<0.001 \\
<0.001^{\mathrm{A}-\mathrm{B}} \\
1.0^{\mathrm{A}-\mathrm{C}} \\
\\
0.588^{\mathrm{A}-\mathrm{D}}\end{aligned}$ \\
\hline $\mathrm{LF} /(\mathrm{HF}+\mathrm{MF})$ & $\begin{array}{l}\text { Mean } \\
\text { SD }\end{array}$ & $\begin{array}{l}4.18 \\
1.99\end{array}$ & $\begin{array}{l}3.55 \\
1.66\end{array}$ & $\begin{array}{l}5.09 \\
2.35\end{array}$ & $\begin{array}{l}4.66 \\
2.49\end{array}$ & $\begin{aligned} & \mathbf{0 . 0 0 1} \\
& 1.0^{\mathrm{A}-\mathrm{B}} \\
< & \mathbf{0 . 0 0 1} \\
& 1.0^{\mathrm{A}-\mathrm{C}} \mathrm{C}\end{aligned}$ \\
\hline ApEn & $\begin{array}{l}\text { Mean } \\
\text { SD }\end{array}$ & $\begin{array}{l}1.31 \\
0.15\end{array}$ & $\begin{array}{l}1.39 \\
0.16\end{array}$ & $\begin{array}{l}1.27 \\
0.17\end{array}$ & $\begin{array}{l}1.14 \\
0.21\end{array}$ & $\begin{aligned}< & \mathbf{0 . 0 0 1} \\
< & \mathbf{0 . 0 0 1} \mathbf{1}^{\mathrm{A}-\mathrm{B}} \\
& 0.749^{\mathrm{A}-\mathrm{C}} \\
< & \mathbf{0 . 0 0 1}^{\mathrm{A}-\mathrm{D}}\end{aligned}$ \\
\hline
\end{tabular}

$P$-value for comparison among groups using the one-way analysis of variance (ANOVA) test. $P$-value for the one-way ANOVA test with the Bonferroni adjusted $\alpha$ are indicated with A-B (white versus Black), A-C (white versus Asian), A-D (white versus Latina) groups. *Values in bold are statistically significant. Variables are calculated using the initial, the middle and the final 3 min of each trace. ApEn, approximate entropy; cCTG, computerized cardiotocographic; HF, high frequency; II, interval index; LF, low frequency; LF/(HF + HF), LF/(HF + MF) ratio; LTI, long-term irregularity; MF, movement frequency; SD, standard deviation; STV, short-term variability.

correlation with $\mathrm{LF}(r=-0.542, P<0.001)$ and a positive correlation with HF $(r=0.612, P<0.001)$. LF showed negative correlations with $\mathrm{MF}$ and $\mathrm{HF}(r=-0.790$, $P<0.001$; and $r=-0.703, P<0.001)$ and a positive correlation with the $\mathrm{LF} /(\mathrm{HF}+\mathrm{MF})$ ratio $(r=0.578$, $P<0.001)$, respectively. Among African pregnant women, ApEn showed a negative correlation with LF $(r=-0.593, P<0.001)$ and a positive correlation with
HF $(r=0.471, P<0.001)$. LF showed negative correlations with $\mathrm{MF}$ and $\mathrm{HF}(r=-0.755, P<0.001$; and $r=-0.788, P<0.001)$ and a positive correlation with the $\mathrm{LF} /(\mathrm{HF}+\mathrm{MF})$ ratio $(r=0.564, P<0.001)$, respectively. Among Asian pregnant women, Delta showed a positive correlation with LTI $(r=0.841, P<0.001)$ and a negative correlation with $\mathrm{MF}(r=-0.507, P<0.001)$. ApEn showed a negative correlation with LF 
Table 3 Correlation coefficients between the variables evaluated

\begin{tabular}{|c|c|c|c|c|c|c|}
\hline Group & & LTI & $\mathrm{LF}$ & MF & $\mathrm{HF}$ & $\mathrm{LF} /(\mathrm{HF}+\mathrm{HF})$ \\
\hline \multirow[t]{4}{*}{ White } & ApEn & -0.177 & -0.542 & 0.232 & 0.612 & -0.387 \\
\hline & $P$ & $<0.001$ & $<0.001$ & $<0.001$ & $<0.001$ & $<0.001$ \\
\hline & LF & 0.311 & 1 & -0.790 & -0.703 & 0.578 \\
\hline & $P$ & $<0.001$ & & $<0.001$ & $<0.001$ & $<0.001$ \\
\hline \multirow[t]{4}{*}{ Black } & ApEn & -0.158 & -0.593 & 0.443 & 0.471 & -0.466 \\
\hline & $P$ & 0.013 & $<0.001$ & $<0.001$ & $<0.001$ & $<0.001$ \\
\hline & LF & 0.157 & 1 & -0.755 & -0.788 & 0.564 \\
\hline & $P$ & 0.014 & & $<0.001$ & $<0.001$ & $<0.001$ \\
\hline \multirow[t]{6}{*}{ Asian } & Delta & 0.841 & 0.483 & -0.507 & -0.299 & -0.064 \\
\hline & $P$ & $<0.001$ & 0.001 & $<0.001$ & 0.134 & 0.678 \\
\hline & ApEn & -0.370 & -0.672 & -0.449 & 0.683 & -0.014 \\
\hline & $P$ & 0.012 & $<0.001$ & 0.002 & $<0.001$ & 0.925 \\
\hline & LF & 0.421 & 1 & -0.874 & -0.724 & 0.022 \\
\hline & $P$ & 0.004 & & $<0.001$ & $<0.001$ & 0.888 \\
\hline \multirow[t]{6}{*}{ Latina } & ApEn & -0.263 & -0.421 & 0.097 & 0.748 & -0.524 \\
\hline & $P$ & 0.250 & 0.057 & 0.674 & $<0.001$ & 0.015 \\
\hline & LF & 0.319 & 1 & -0.895 & -0.662 & 0.673 \\
\hline & $P$ & 0.158 & & $<0.001$ & $<0.001$ & $<0.001$ \\
\hline & MF & -0.134 & -0.895 & 1 & 0.257 & -0.579 \\
\hline & $P$ & 0.561 & $<0.001$ & & 0.261 & $<0.001$ \\
\hline
\end{tabular}

Values in bold are statistically significant. P-value for comparison between parameters for each group using the Pearson correlation test. ApEn, approximate entropy; HF, high frequency; LF, low frequency; LF/(HF + HF), LF/(HF + MF) ratio; LTI, long-term irregularity; MF, movement frequency; SD, standard deviation.

$(r=-0.672, P<0.001)$ and a positive correlation with $\mathrm{HF}$ $(r=0.683, P<0.001)$, while LF showed negative correlations with $\mathrm{MF}$ and $\mathrm{HF}(r=-0.874, P<0.001$; and $r=-0.724, P<0.001)$. Among Latina pregnant women, ApEn showed a positive correlation with HF $(r=0.748$, $P<0.001)$ and a negative correlation with the LF/(HF $+\mathrm{MF})$ ratio $(r=-0.524, P=0.015)$. LF showed negative correlations with MF and $\mathrm{HF}(r=-0.895, P<0.001$; and $r=-0.662, P<0.001)$ and a positive correlation with the $\mathrm{LF} /(\mathrm{HF}+\mathrm{MF})$ ratio $(r=0.673, P<0.001)$. Finally, $\mathrm{MF}$ showed a negative correlation with the $\mathrm{LF} /(\mathrm{HF}+\mathrm{MF})$ ratio $(r=-0.579, P<0.001)$.

We also considered a stratified analysis based on the sex-specific differences in FHR parameters, but no statistically significant results were found.

In order to give an idea of the true clinical potential of cCTG analysis in the detection of ethnic differences, ROC and specificity were calculated for the most significant cCTG parameters investigated (Figure 1).

In the comparison between white and black women groups, Delta (area under the ROC [AUC]: 0.688; specificity: 0.88) and LTI (AUC: 0.805; specificity: 0.91) showed the best performances for the former, while LF (AUC: 0.664; specificity: 0.58), MF (AUC: 0.597; specificity: 0.60), HF (AUC: 0.654; specificity: 0.58), and ApEn (AUC: 0.650; specificity: 0.49) showed the largest AUC in the ROC for the latter. Similar results were obtained in the comparison between white and Asian groups with the largest AUC in the ROC for Delta and LTI in the first case and for MF (AUC: 0.704; specificity: 0.62) and the $\mathrm{LF} /(\mathrm{HF}+\mathrm{MF})$ ratio (AUC: 0.652 ; specificity: 0.74$)$ in the second case. Finally, in the comparison between white and Latina women groups, Delta showed the largest AUC in the ROC for the former, and ApEn (AUC: 0.786 ; specificity: 0.78 ) was more significant for the latter.

\section{Discussion}

Clinical practice requires a complex examination of pregnancy based on the combination of several fetal wellbeing methods. Thus, many authors have tried to analyze the role of cCTG associated with the most established and well-known methods, such as Doppler ultrasonography, underlining the high impact of this method in the clinical decision process. Siristatidis et al. ${ }^{20}$ demonstrated that CTG, when combined with Doppler velocimetry, increases the clinician's ability to accurately identify fetal hypoxia and decreases the rate of cesarean section.

Our investigation offers a multiparametric analysis of cCTG signal through different linear and nonlinear approaches in a population of women with term physiological pregnancies, according to ethnic differences.

The percentage of vaginal delivery was similar in all groups investigated. Similarly, there were no significant 

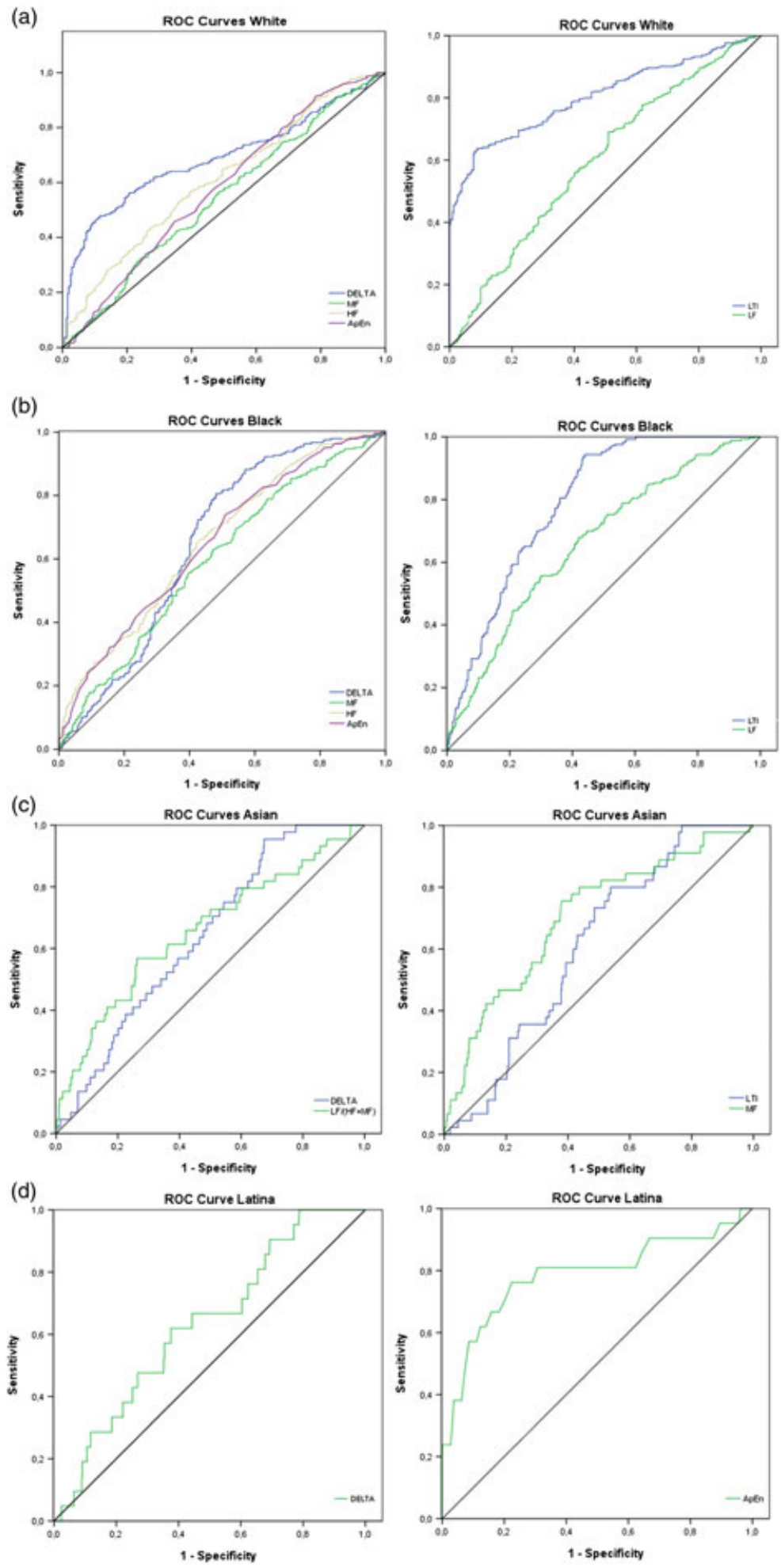

Figure 1 Receiver-operator curves (ROC) for the most significant computerized cardiotocographic (cCTG) parameters investigated in (a) white, (b) black, (c) Asian, and (d) Latina groups: Delta and long-term irregularity (LTI) were better in the white group; low frequency (LF) and high frequency (HF) were better in the black group; movement frequency (MF) and the LF/(HF $+\mathrm{MF})$ ratio were better in the Asian group; approximate entropy (ApEn) was better in the Latina group. 
differences among the groups in terms of Apgar scores and umbilical cord $\mathrm{pH}$ values at birth. Our findings contradicted those of other studies ${ }^{21,22}$ in which black women were more likely to undergo a cesarean delivery for non-reassuring FHR tracings than were white women, probably as a consequence of low-quality CTG interpretation by the naked eye. On the contrary, the cCTG analysis offers a standardized evaluation every minute on 3-min-signal segments and excludes the periodic variation of the FHR signal (such as accelerations and decelerations), which can mislead clinicians about the real state of fetal well-being.

A significant decrease of FHR baseline occurs during pregnancy, as a consequence of progressive increase in the parasympathetic influence on FHR. In our study, FHR baseline values were similar for all pairwise comparisons, confirming the same degree of fetal neural maturity. On the contrary, other studies ${ }^{3,23}$ have reported higher FHR baseline values for fetuses of black women.

Medium- and long-term variability values were different for all pairwise comparisons between the white and other ethnic groups. In particular, Delta and LTI showed lower and higher values for fetuses of white women than those of black women, respectively. We also noted that fetuses of black women had the lowest LTI values and a significant reduction in the number of small and large accelerations, calculated on 20-min windows of recording, compared to fetuses of other ethnic origins (data not shown).

No statistically significant differences were found for the STV values among groups, ${ }^{4}$ while Marie et al. reported lower STV values in the fetuses of the black, compared with the white women. ${ }^{3}$ It is important to note that our method to calculate STV differs from that of the international standard as introduced by Dawes and Redman. ${ }^{24}$ This is an important finding, because STV is the most significant indicator of fetal homeostasis, especially when it is compared to long- and medium-term variability. In fact, STV is the most extensively studied parameter of CCTG because it is able to assess the integrity of the autonomic nervous system (ANS) and its connections with the central nervous system (CNS): high STV values reflect a healthy ANS, and normal activity of chemoreceptors, baroreceptors, and cardiac responsiveness, while low STV values are associated with impending deterioration of fetal oxygen supply and therefore fetal distress. ${ }^{25,26}$

Spectral components of the CCTG signal are strongly related to neuronal control of cardiovascular system activity. They provide quantitative indicators of neuronal control of the sinoatrial node, which can be useful to help the physician's evaluation of fetal well-being. Numerous experimental and clinical studies have consistently indicated the LF component as a marker of sympathetic modulation and $\mathrm{HF}$ as a marker of vagal modulation. ${ }^{2}$ In our study, spectral analysis of FHR variability provided significant variations among the ethnic groups. In particular, fetuses of black women performed the lowest LF and the highest HF values in the comparison of the groups. These results suggested the prevalence of the parasympathetic tone on the sympathetic ones and probably confirmed the full neuronal maturity of black fetuses.

MF quantifies fetal movements, basically of the trunk. It depends also on maternal breathing, as a high correlation between the fetal MF component and the maternal respiratory frequency was found. ${ }^{2,26,28}$ In our study, fetuses of black women had higher MF values than fetuses of white and Asian women. This finding emphasizes the state of well-being of black fetuses as reported by the pregnant women, who confirmed a high number of fetal movements at term pregnancy.

The $\mathrm{LF} /(\mathrm{HF}+\mathrm{MF})$ ratio is a synthetic index of the balance between physiological control components and fetal activity level. Its marked reduction in black fetuses was the consequence of an imbalance of sympathovagal activity with predominance of parasympathetic tone combined with good levels of fetal activity.

ApEn was considered to provide a measurement of feedback and regularity, so that time series, containing many repetitive patterns, has relatively low ApEn, and a less predictable process has higher ApEn. ${ }^{18,29} \mathrm{Li}$ et al. ${ }^{30}$ suggested that the lower ApEn of FHR was associated not only with fetal distress and hypoxia, but also with respiratory and metabolic acidosis in women at term pregnancy.

In our study, fetuses of black women performed higher ApEn values than fetuses of white, Asian, and Latina women, confirming the integrity and normal functionality of all components of CNS and their central integrations with the sympathetic and parasympathetic branches of the ANS.

In the correlation study among CCTG parameters, ApEn was positively correlated with $\mathrm{HF}$ and negatively with LF in all ethnic groups investigated. Moreover, LF was negatively correlated with both MF and HF in all groups and it was positively correlated with the $\mathrm{LF} /(\mathrm{HF}+\mathrm{MF})$ ratio in almost all groups investigated.

Our results confirmed that the maturity of a term fetus is expressed through the prevalence of the parasympathetic tone on the sympathetic one and a higher state of neuronal complexity for all ethnic groups examined. 
A complete evaluation of the clinical usability of CCTG through ethnic differences should include the analysis of its limits. For a long time, CTG was subjected to several criticisms due to the high number of false positive results, which caused both the increase of unnecessary interventions for mother and fetus and the inappropriate use of health-care resources. ${ }^{5}$ The cCTG parameters have been found useful in the discrimination among ethnic groups. In particular, Delta and LTI performed better in the white group than in the black, Asian, and Latina groups. On the other hand, LF, MF, HF, and ApEn performed better in the black than in the white group.

These results showed that in the ante-partum assessment of fetuses of different ethnic origins, both linear and nonlinear components of the FHR variability should be evaluated in order to avoid misinterpretations of the CTG trace.

In a sub-sample of our cohort, we did not find significant influences of fetal state or intra-individual variation within CCTG tracings apart from LTI. We, therefore, cannot entirely rule out that inter- or intra-individual differences, especially when considering different fetal states of activity, may have profoundly influenced our findings.

Our results provide a first step in the analysis of CCTG parameters with respect to ethnic differences. This method could improve the accuracy of the fetal wellbeing assessment in an objective way, and especially could help the clinician's decision about the timing and method of delivery. Certainly, there are questions still unanswered, for example understanding why these disparities exist, how race and ethnicity affect the FHR variability and what is the role of environmental influences.

\section{Acknowledgments}

All authors have fulfilled all conditions required for authorship.

\section{Disclosure}

None of the authors has any financial or personal relationships with other people or organizations that could inappropriately influence (bias) this work. There are no potential conflicts of interest, including employment, consultancies, stock ownership, honoraria, paid expert testimony, patent applications/registrations, or grants or other funding for any of the authors.

\section{References}

1. Figueras F, Albela S, Bonino S et al. Visual analysis of antepartum fetal heart rate tracings: Inter- and intra-observer agreement and impact of knowledge of neonatal outcome. $J$ Perinat Med 2005; 33: 241-245.

2. Signorini MG, Magenes G, Cerutti S, Arduini D. Linear and nonlinear parameters for the analysis of fetal heart rate signal from cardiotocographic recordings. IEEE Trans Biomed Eng 2003; 50: 365-374.

3. Marie C, Sinoquet C, Barasinski C, Lémery D, Vendittelli F. Does maternal race influence the short-term variation of the fetal heart rate? An historical cohort study. Eur J Obstet Gynecol Reprod Biol 2015; 193: 102-107.

4. Ogueh O, Steer PJ. Ethnicity and fetal heart rate variation. Obstet Gynecol 1998; 91: 324-328.

5. Grivell RM, Alfirevic Z, Gyte GM, Devane D. Antenatal cardiotocography for fetal assessment. Cochrane Database Syst Rev 2010; CD007863. DOI:10.1002/14651858.CD007863.pub3.

6. Butt K, Lim K, Society of Obstetricians and Gynaecologists of Canada. Determination of gestational age by ultrasound. $J$ Obstet Gynaecol Can 2014; 36: 171-183.

7. Zeskind PS, Gingras JL. Maternal cigarette-smoking during pregnancy disrupts rhythms in fetal heart rate. J Pediatr Psychol 2006; 31: 5-14.

8. Serra V, Bellver J, Moulden M, Redman CWG. Computerized analysis of normal fetal heart rate pattern throughout gestation. Ultrasound Obstet Gynecol 2009; 34: 74-79.

9. Costa VN, Nomura RMY, Reynolds KS, Miyadahira S, Zugaib $\mathrm{M}$. Effects of maternal glycemia on fetal heart rate in pregnancies complicated by pregestational diabetes mellitus. Eur J Obstet Gynecol Reprod Biol 2009; 143: 14-17.

10. Kessous R, Aricha-Tamir B, Weintraub AY, Sheiner E, Hershkovitz R. Umbilical artery peak systolic velocity measurements for prediction of perinatal outcome among IUGR fetuses. J Clin Ultrasound 2014; 42: 405-410.

11. Wang D, Zhu L, Zhang $\mathrm{S}$ et al. Predictive macrosomia birthweight thresholds for adverse maternal and neonatal outcomes. J Matern Fetal Neonatal Med 2016; 28: 1-24.

12. Arduini D, Rizzo G, Piana G, Bonalumi A, Brambilla P, Romanini C. Computerized analysis of fetal heart rate: I. Description of the system (2CTG). J Mat Fet Inv 1993; 3: 159-163.

13. Royal College of Obstetricians and Gynaecologists. The use of electronic fetal monitoring. Evidence-based clinical guideline, number 8. London: RCOG Press, 2001.

14. Signorini MG, Fanelli A, Magenes G. Monitoring fetal heart rate during pregnancy: Contributions from advanced signal processing and wearable technology. Comput Math Methods Med 2014; 2014: 707581.

15. Fanelli A, Magenes G, Campanile M, Signorini MG. Quantitative assessment of fetal well-being through CTG recordings: A new parameter based on phase-rectified signal average. IEEE $J$ Biomed Health Inform 2013; 17: 959-966.

16. Mantel R, Van Geijn HP, Caron FJ, Swartjes JM, Van Woerden $\mathrm{EE}$, Jongsma HW. Computer analysis of antepartum fetal heart rate: 1. Baseline determination. Int J Biomed Comput 1990; 25: 261-272.

17. de Haan J, van Bemmel J. H, Versteeg B et al. Quantitative evaluation of fetal heart rate patterns. I. Processing methods. Eur J Obstet Gynecol Reprod Biol 1971; 1: 95-102. 
18. Yeh S, Forsythe A, Hon EH. Quantification of fetal heart rate beat-to-beat interval differences. Obstet Gynecol 1973; 41: 355-363.

19. Pincus S. Approximate entropy (ApEn) as a complex measure. Chaos 1995; 5: 110-117.

20. Siristatidis C, Kassanos D, Salamalekis G, Creatsa M, Chrelias C, Creatsas G. Cardiotocography alone versus cardiotocography plus Doppler evaluation of the fetal middle cerebral and umbilical artery for intrapartum fetal monitoring: A Greek prospective controlled trial. J Matern Fetal Neonatal Med 2012; 25: 1183-1187.

21. Washington S, Caughey AB, Cheng YW, Bryant AS. Racial and ethnic differences in indication for primary cesarean delivery at term: Experience at one U.S. institution. Birth 2012; 39: $128-134$.

22. Getahun D, Strickland D, Lawrence JM, Fassett MJ, Koebnick C, Jacobsen SJ. Racial and ethnic disparities in the trends in primary cesarean delivery based on indications. Am J Obstet Gynecol 2009; 201: 422 e1-422 e7.

23. Johnson MJ, Paine LL, Mulder HH, Cezar C, Gegor C, Johnson TR. Population differences of fetal biophysical and behavioral characteristics. Am J Obstet Gynecol 1992; 166: 138-142.
24. Pardey J, Moulden M, Redman CW. A computer system for the numerical analysis of nonstress tests. Am J Obstet Gynecol 2002 May; 186: 1095-1103.

25. Serra V, Moulden M, Bellver J, Redman CW. The value of the short-term fetal heart rate variation for timing the delivery of growth-retarded fetuses. BJOG 2008; 115: 1101-1107.

26. Anceschi MM, Piazze JJ, Ruozi-Berretta A et al. Validity of short term variation (STV) in detection of fetal acidemia. J Perinat Med 2003; 31: 231-236.

27. Breborowicz G, Moczko J, Gadzinowski J. Analysis of fetal heart rate in frequency domain. In: van Geijn HP, Copray FJ (eds). A critical appraisal of fetal surveillance. New York: Elsevier, 1998; 325-332.

28. Sibony O, Fouillot JP, Benaoudia M et al. Quantification of the fetal heart rate variability by spectral analysis of fetal wellbeing and fetal distress. Eur J Obstet Gynecol Reprod Biol 1994; 54: 103-108.

29. Pincus SM. Assessing serial irregularity and its implications for health. Ann N Y Acad Sci 2001; 954: 245-267.

30. Li X, Zheng D, Zhou S, Tang D, Wang C, Wu G. Approximate entropy of fetal heart rate variability as a predictor of fetal distress in women at term pregnancy. Acta Obstet Gynecol Scand 2005; 84: 837-843. 